\title{
An Analysis on the Thinking Process of Language Acquirement
}

\author{
Liu Xue Dan and Hu Cui Xia
}

\begin{abstract}
When a person is acquiring a language, it is interesting to know the thinking process of his mind through his listening, speaking, reading and writing in the target language. This thesis analyzes the thinking process when people are acquiring another language and the author hopes to contribute to the analysis on people's cognition and acquirement on language .
\end{abstract}

Index Terms - Thinking process, listening, speaking, reading, writing, analysis, language learning.

\section{INTRODUCTION AND RESEARCH BACKGROUND}

There are many aspects in acquiring another language and among which the thinking process might be the most important one. If a person listens, thinks, reads and speaks in another language without thinking he is not doing an effective learning. In another word, this is the so called cognition defined as the mental process involved in knowing, learning, and understanding things. Singer(1991) said "The study of language is concerned with psychology because language is the product of human brains and psychology is the study of human brains”(From Wu Qian Long, 2000) [1]. If we take a closer look at the mental process or the thinking process in the people's mind while he is learning the language, it will be easy to find there are certain phenomena worthy analyzing. How will the beginners think when they are asked to write down the English numbers they just heard? Why do some advanced learners read so quick to understand the difficult articles? Is it much easier for a kid to learn a foreign language. The author will just state some facts observed and avoid making any judgment so as to be objective and realistic in this thesis.

\section{ANALysis AND RESEARCHES ON THE LANGUAGE ACQUIRING PROCESS}

\section{A. Analysis and Researches on the Language Acquiring Process through Listening}

Listening is often defined as the ability to decode the message of the speaker. It involves two things-hearing the sounds, which is passive and understanding, which is an active process(Underwood,1989). When we are listening, "we cannot usually predict what we will have to listen to”(Anderson and Lynch, 1988). We must be prepared to

Manuscript received December 1, 2017; revised February 7, 2018.

The authors are with the China Jiliang University, China (e-mail: 3583572@qq.com). extract meanings as best we can from the target language. It is therefore not enough to merely be able to understand the same range of language that we can speak. Our receptive repertoire must match the productive repertoire of the speaker. Listening demands active involvement of the listener in order to construct the message that the speaker intends [2].

In one of my researches on language learner on beginning level, I played a sound recording containing 8 numbers and required the 40 20-year-old learners(with Chinese as the mother tone) to write the numbers down. All of them find it is very hard to follow the recording, let alone to write them down. The reason is that they tend to translate the heard English number into Chinese ones and then write it down. None of them can associate the sound directly with the concept in their mind. This experiment tells us that when an adult with only one language, he associates the language with the concept and it will be very hard for him to change this habit. In this situation, the receptive repertoire can not match the productive repertoire immediately. So when he hear the words in another language, he will try hard to find the corresponding word in his mother tone and use it to help to react. This might not be an effective way to acquire another language.

But the same practice is a different picture in younger Children. In another research, 20 5-year-old kindergarten kids(with Chinese as the mother tone) are asked to choose whatever they heard in English and they tend to react very quickly. After several similar practices, the children tend to repeat the English word and make their own sentences in English. This may be the effective way of learning a language and we are curious to know how do the children know the way to acquire such skill?

\section{B. Analysis and Researches on the Language Acquiring Process through Speaking}

Speaking is a key factor for people's acquiring of language but it is a pity that most language learners, with or without awareness ignore it. "Speaking as a main language output needs the learner to activate pronunciation, grammar, sentence structure immediately and produce the standard language"(Liu Jing Hua) Many people when they are learning a foreign language in the first time do not talk in this language due to the sense of incompetence. An research was conducted on the participants when they are using English as the first foreign language to speak. It is good to find that speaking can develop the speakers' ability of utilizing the language. 20 adult participants(beginner level) were asked to discussed an interesting topic, due to the passion to express, the participants were eager to speak out their idea. In a later survey, 
participants with the beginner level said that they will also translate the idea from Chinese to English. During the process they might feel uneasy because the logics same obscure since they tried to speak English in an Chinese way. Thus there is a question on the thinking order of the two language. For Example, in telling an address, in Chinese, speakers tend to tell the locations from a larger one to a small one: China, Chengdu, Wuhou district, Shunxin Road, No.45 while in English speakers take the opposite order-from a small one to a large one: No 34, linden street, Bronx, New York. The similar situation can be defined in the way to tell time, days and even a whole sentence order. The participants will show some difficulties to transfer that kind of order first but after a period of time of practicing, the reflecting time became obviously shorter than the first time they use to do the practice. In the advanced learners, the situation is different. The advanced learner can easily transfer to the other mode of their second language. They developed a thinking skill in English through many years of practice.

Another case might also be the younger kids which just as mentioned above, they tend to absorb and make sentences themselves if instructed properly. They do this practice mainly for fun and enjoy doing it. But concerning specific number or address or times, the kids are still speaking their mother tongue. This phenomenon might be explained by the developing stage of cognition of kids compared with the adults Still, it is wondered if the language acquirement speed is connected with the developing stage of cognition [3].

\section{Analysis and Researches on the Language Acquiring Process through Reading}

Reading is a processing of cognition and acquirement. "Reading is the soul of a nation and the way for a nation to acquire knowledge".(Wang Cui Ping) We can see the importance of reading in the development of people's mind The defect is that many learners don't connect the printed words with the concept during reading especially the beginners. In the research conducted on adults and teenagers(beginner level), the participants will read and translate. The reading speed is very slow and they often miss the point and feel blank in their mind when the article is full of difficult words and complex sentence structures. The most difficult sentence structure block their understanding such as the clauses, the prepositions and conjunctions. It is interesting to find that to solve these problems, the participants only need to know three main sentence structures and the usage of certain words mainly concerned with the infinitive, the verb "be" and "have", the preposition, etc. This solution have to remind us if these words are concerned with certain thinking reaction in human brains. After reading an article with complex sentence structure, the confused readers are trained with grammar illustration on sentence structures, infinitive, the verb "be" and "have", the preposition and the conjunctions. This training re-constructed the learner's thinking and logic order about English language and taught them to think in another order and way. After several days of alike practice, the participant changed their usual order of observing a language and their thinking. The reading speed and understanding were improved. The printed words were better connected with the participants cognition and the concept in the mind. But the participants are still reading it passively which means they are not think when reading those words. The reason is due to the limit in this language ability.

This thinking process might be much more complex when a person is reading. First he has to connect the printed words with the concept and figured out the meaning according to the context. After this two process, he will develop his own logic order on the article. The logic order development is quiet difficult one since the readers are foreigners to the target language.

\section{Analysis and Researches on the Language Acquiring Process through Writing}

Writing might be most complex job for a foreign language learned to acquire and we will analyze the thinking process of the language learner when they are using a foreign language to write. "The main challenge of teaching is to help the students transfer their knowledge into their awareness and transfer what they know, remember, feel and believe into writing, dialogue or pictures"(Stein).the beginners are stilling trying hard to write English after translating their thought in English. This level is an intro one and apart from the punctuation there were many grammar mistakes and logic disorders. For example, there are always mistakes like using the verb twice which means the writer doesn't realize the logical relation of the verb and the subjective. Moreover, the learner can not define the logical order of the whole writing, see the following example:

"I lost my wallet and ate instant noodles yesterday. My money was in it so I have to eat instant noodles for the whole week.”

We can see in the sentence the use of " $\mathrm{it}$ " is not appropriate and the readers will assume the money was in the instant noodles. In fact the writer really means that the money was in the wallet. It is quiet strange this two-letter word can arouse the reflection of connection between "it" and "instant noodles" although there is obviously logic disorder.

The intermediate level learners can organize their language basically in English, they have less grammar mistakes but the biggest problem is their logic. The writings of intermediate level learners are mostly in lack of the conjunction to illustrate the time order, reason, result, etc. This reflects the defects in the logical order of the learners in the foreign langue and the learners are still using their mother tongue inside. The writing process is concerned with the advanced thinking of the learner in the foreign language and from the writing we can see the demerits in the thinking of the writers when they are using a non-mother tongue language [4].

\section{IMPLICATION AND ENLIGHTENMENT}

In this part, the author will try to write as much as possible on the implication and enlightenment based on the facts discussed above. It is better not to give solutions or judgment since we are doing researches on facts. 


\section{A. Implication and Enlightenment on the Thinking Process in Listening}

The recognizing of the word through listening and transfer the heard words into the concept in the brain can bring us a philosophical question. Is it the listening that makes us to know the object or is it the object itself makes us to know the language. The answer may be mysterious and we can take a look at a young baby who is acquiring his mother tongue. We can find that he sometimes learn the language by listening and repeating but sometimes he explore by himself. But for an adult, the learning method is mainly through his listening and it is obvious that if a person without the word-object connection in his mind, he will learn the foreign language faster than who has already had the mother tongue word-object connection in his mind. Does this phenomenon implicates anything? Is it related to our cognition ability?

\section{B. Implication and Enlightenment on the Thinking Process in Speaking}

The speaking of the language is the output of one's language acquirement. When a person successfully put out the language he acquired we can notice that the speaker will not be aware of the tense, the subjective, the objective or any other grammar points. How can this awareness and cognition form in such a subtle way. Is it merely a habit through thousands of practicing? When a person acquire another way of speaking, how can this new "habit" change his way of thinking, his way of considering things? Will the new speaking habit make any impact on the speakers physically and mentally? If the speaker is physically affected by the new speaking way, will this impact him mentally? We can see the phenomenon that implicate as this: When a learner speaks a words or sentence he tends to remember or understand the words or sentence better. Besides, we always see the children trying to make sentences themselves and after such kind of practice they tend to understand and manage the language.

\section{Implication and Enlightenment on the Thinking Process in Reading}

The complicated sentence structure is decoded by the reader by heart. We can find the written language is much more complicated than the listening and speaking language. When reading the language, the reader is supposed to judge the appropriate meaning according to the context and define the metaphor. This thinking process is special for human beings because different people may have different interpretation on the context. It is even more interesting when such process occurred in reading a non-mother tongue language. How do the reader develop the ability to decode the long and complex sentence. Do their reflection and thinking mode change when they are reading a foreign language. Will they consider the thinking mode in their mother tongue when they are reading foreign language to help their understanding or just totally forget the mode of their mother tongue? Karl Max once said: "The best way to learn a foreign language is to use the language and forget the mother-tongue.” But we still wonder, as an adult, we gain our knowledge about this world primarily through our mother language and the cognition is base on the form and rules of our mother language. Can a person reconstruct his cognition mode when he is learning a foreign language or if the cognitive mode is universal for people to know the world and think about things.

\section{Implication and Enlightenment on the Thinking Process in Writing.}

The written language is a great invitation to transfer our knowledge and thus the human being become civilized. The output of the written language might be a little different from the speaking. People tend to be more accurate and more careful when they are writing down the language. And as the sentence becomes longer, the thought also develops complicated. The change is rather subtle when the language was written down. In Chinese, a long sentence is not welcomed and according to ancient writings, Chinese people can use one or two characters to express a complicated idea or event. In English, there appears a lot of long sentence and people can even write a book by using one sentence. This development is quiet amazing but we also have to wonder. What will the short sentence(or characters) and the long sentence(English) influence the human thinking? Will people become more emotional and better at feelings if they always use short sentence(characters) because people have to interpret the meaning implicated in the short sentence(characters). Will people be more indifferent but reasonable if they always define which is the subjective and which is the objective? We try not to be authoritative, each language is the heritage of our ancient ancestors. They made the language this way because of their own merit and there are certainly secret code in the language waiting for us to explore [5].

\section{CONCLUSION}

From the above discussion, we get a rough picture of the thinking process of language learning in some kinds of learners in listening, speaking, reading and writing. Analyzing the process is quiet important for clarifying our thinking order and learning mode when we are acquiring a foreign language. The author also tries to avoids making any judgment in order to be objective and realistic. In part III, the author just states out some thought and consideration about the implications and enlightenments about the four thinking processes. Maybe the exploration is not deep but the author hope this article can arouse other researcher's attention and more colleagues can join into the study on language and thinking.

\section{ACKNOWLEDGMENT}

This article is for the project of The Comparative Study on English Pronunciation and Chinese Pronunciation funded by China Jiliang University Science and Arts Project Funding Program, 2003.

\section{REFERENCES}

[1] W. Q. Long, "Some problems in the second language acquirement from the relation between language and thought," Foreign Language Teaching, vol. 5, pp. 182-188, 2000. 
[2] H. Y. Wang, "The importance of listening teaching in cognition process," Foreign Language Teaching, 2002.

[3] J. H. Liu, "The thinking guiding graph applied in oral English teacher," Journal of Weifang Engineering Vocational College, vol. 6, Nov. 2016.

[4] C. P. Wang, S. Hu, and J. Song, "On the application of mind map in reading activities," Research on Library Science, vol. 14, 2011.

[5] P. Stein, "Rethinking resources: Multimodal pedagogies in the ESL classroom.” TESOL Quarterly, vol. 34, 2000

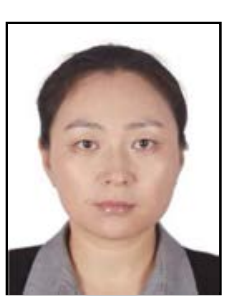

Liu Xue Dan was born in Chongqing, China on June 11, 1979. She obtained her bachelor degree in Sichuan International Study University (1998-2002) as an English major in Chongqing, China in 2002 and received a master degree in foreign linguistics and applied linguistics in Shanghai Maritime University (2005-2007) in Shanghai, China.

She worked as a teacher in several universities as follows: China Jiliang University (2002-2005); Arts and Science College of Sichuan Normal University (2008-2013):Yangtze Normal University (2014-2016). Some of the publications are: "A discussion on the reform of college English teaching from the aspect of textbook" Journal of Jiamusi Education Institute, vol. 5, 2011; “A discussion on the teacher's book of college English tex book" Youth and Society, vol. 8, 2011. She is interested currently in language and thought, language philosophy and applied linguistics. Ms. Liu also received award as excellent student in Sichuan International Study University in 2000 and was awarded excellent teacher in China Jiliang University in 2004.

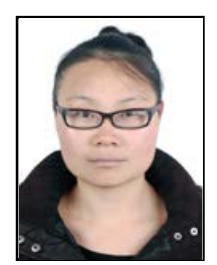

Hu Cuixia was born in Henan, China on September 29, 1982. She obtained her master degree in Chongqing University as an English major in 2009. Her major research direction is English teaching and information technology and is greatly interested in applied linguistics in recent years.

Since graduation (2009. 8-now), she has been working in Tianfu College, Southwest University of Finance and Economics. Because of good teaching performance, she was once awarded as excellent teacher in Tianfu College in 2010 and 2013. She has also led other staff in English Teaching Center to carry out teaching innovation and achieved good results. 